\title{
Steady improvement of infection control services in six community hospitals in Makkah following annual audits during Hajj for four consecutive years
}

\author{
Tariq A Madani*1,2, Ali M Albarrak3, Mohammad A Alhazmi², \\ Tarik A Alazraqi ${ }^{4}$, Abdulahakeem O Althaqafi ${ }^{5}$ and Abdulrahman $\mathrm{H}$ Ishaq ${ }^{2}$
}

Address: ${ }^{1}$ Department of Medicine, Faculty of Medicine, King Abdulaziz University, Jeddah, Kingdom of Saudi Arabia, ${ }^{2}$ Ministry of Health, Riyadh, Kingdom of Saudi Arabia, ${ }^{3}$ Department of Medicine, Armed Forces Hospital, Riyadh, Kingdom of Saudi Arabia, ${ }^{4}$ Department of Medicine, Faculty of Medicine, King Khalid University, Abha, Kingdom of Saudi Arabia and ${ }^{5}$ Department of Medicine, King Abdulaziz Medical City, Jeddah, Kingdom of Saudi Arabia

Email: Tariq A Madani* - taamadani@yahoo.com; Ali M Albarrak - draalbarrak@yahoo.com; Mohammad A Alhazmi - alhazmimm@hotmail.com; Tarik A Alazraqi - tarik4u2u@ hotmail.com; Abdulahakeem O Althaqafi - thaqafiao1@ngha.med.sa; Abdulrahman H Ishaq - rishag@hotmail.com

* Corresponding author

Published: 25 August 2006

BMC Infectious Diseases 2006, 6:135 doi:10.1186/147/-2334-6-135
Received: 26 June 2006

Accepted: 25 August 2006

This article is available from: http://www.biomedcentral.com//47/-2334/6/I35

(c) 2006 Madani et al; licensee BioMed Central Ltd.

This is an Open Access article distributed under the terms of the Creative Commons Attribution License (http://creativecommons.org/licenses/by/2.0), which permits unrestricted use, distribution, and reproduction in any medium, provided the original work is properly cited.

\begin{abstract}
Background: the objective of this study was to evaluate the impact of annual review of the infection control practice in all Ministry of Health hospitals in the holy city of Makkah, Saudi Arabia, during the Hajj period of four lunar Islamic years, I423 to 1426 corresponding to 2003 to 2006.

Methods: audit of infection control service was conducted annually over a 10-day period in six community hospitals with bed capacities ranging from 140 to 557 beds. Data were collected on standardized checklists on various infection control service items during surprise visits to the medical, pediatric, surgical, and critical care units, and the kitchens. Percentage scores were calculated for audited items. The results of the audit for hospitals were confidentially sent to them within four weeks after the end of Hajj.
\end{abstract}

Results: deficiencies observed in the first audit included lack of infection control committees, infection control units, infection control educational activities, and surveillance system and shortage of staff. These deficiencies were resolved in the subsequent audits. The average (range) scores of hospitals in II infection control items increased from 43\% (20-67\%) in the first audit to 78\% (6I93\%) in the fourth audit.

Conclusion: regular hospital infection control audits lead to significant improvement of infection control practice. There is a need to build a rigorous infection control audit into hospitals' ongoing monitoring and reporting to the Ministry of Health and to provide these hospitals with feed back on such audits to continuously strengthen the safety standards for patients, visitors, and employees.

\section{Background}

Two to three million pilgrims gather in Makkah annually in the twelfth month of the lunar Islamic year to perform Hajj, the fifth pillar of Islam. During the Rift Valley fever 
epidemic that occurred in southwestern Saudi Arabia in 2000-2001, a total of 886 cases were reported with $13.9 \%$ mortality rate [1]. The infection was mainly transmitted by mosquito bites and/or direct contact with infected sheep [1]. Even though no cases were reported from the holy city of Makkah, there was a potential for its transmission in this city because hundreds of thousands of sheep are sacrificed by pilgrims as part of the Islamic rituals of Hajj. On the other hand, 37 cases of a novel viral hemorrhagic fever virus, referred to as Alkhumra virus, were reported solely from Makkah in 2001-2002, and the virus was also believed to be transmitted by mosquito bites and/or direct contact with infected sheep [2]. After the emergence of these two diseases, the infection control practice in Makkah hospitals during Hajj was scrupulously reviewed by the Saudi Ministry of Health $(\mathrm{MOH})$ to ensure the highest infection control standards for pilgrims. A committee was formed for that purpose comprising consultants in infectious diseases and infection control from the Ministry of Health, the medical schools in King Abdulaziz, King Saud, and King Khaled universities, the Armed Forces Hospital, and the National Guard Hospital. An audit tool was developed by the committee and used to review the infection control practice in all $\mathrm{MOH}$ hospitals in Makkah during the Hajj period for four consecutive years. This study describes the results and the impact of this audit on infection control practice in the audited hospitals.

\section{Methods \\ The Hajj}

Hajj is the fifth of the five pillars of Islam. Any healthy Muslim adult is obliged to perform Hajj once in his/her life if he/she is financially and physically capable. The Hajj begins on the $8^{\text {th }}$ day of Dhul-Hijjah, the $12^{\text {th }}$ month of the lunar Islamic year, and ends on the $13^{\text {th }}$ day of the same month. Hajj has to be performed in three main locations in Makkah, namely, the sacred Kaaba (in the holy city of Makkah), and Mena and Arafat, which are approximately 5 and 18 Kilometers far from Makkah, respectively. Approximately, 2-3 million pilgrims perform Hajj every year; one third of them come from within Saudi Arabia and two thirds come from other countries. Most pilgrims stay in fire-resistant air-conditioned camping tents in Mena during the entire Hajj period. Financially deprived pilgrims who can not afford to pay for the cost of staying in camps usually stay outdoor. Free medical care services are provided to pilgrims by the Saudi Ministry of Health.

\section{Study period}

The study was conducted over a 10-day period annually for four consecutive years during the Hajj period of the lunar Islamic year 1423 to 1426, corresponding to 2003 to 2006 .

\section{Audited Makkah hospitals}

All MOH hospitals in Makkah were included in the audit, namely, Ajiad General Hospital (AGH), Alnoor Specialist Hospital (NSH), King Abdulaziz Hospital (KAH), King Faisal Hospital (KFH), the Maternity and Children Hospital $(\mathrm{MCH})$, and Heraa General Hospital (HGH). Clinical services in $\mathrm{AGH}, \mathrm{HGH}, \mathrm{KAH}, \mathrm{KFH}$, and $\mathrm{NSH}$ included internal medicine, general surgery, orthopedic surgery, obstetrics and gynecology, pediatrics, critical care, ophthalmology, and ear, nose, and throat. In addition, the HGH had a neurosurgical service, and the NSH had both neurosurgical and vascular surgery services. The clinical services in the $\mathrm{MCH}$ included general pediatrics, neonatal and pediatric critical care, and obstetrics and gynecology. In addition to serving the population of Makkah, these six tertiary care hospitals provide medical care to pilgrims who come to Makkah to perform Hajj during the Hajj period and those who come to Makkah year-round to perform Omra which is similar to Hajj except for the fact that the pilgrims are not required to stay in Mena and Arafat and that there is no specified period of time to perform it. The Hajj period is considered to be a peak-period where additional health care workers are temporarily recruited mainly from other regions in Saudi Arabia and a few from outside the country to cover the extensive medical services provided to pilgrims during this period.

\section{Data collection}

The audit tool used in this study was adapted from an Australian audit tool designed by the Victorian State Government Department of Human Services [3]. Data were collected on standardized checklists on various infection control service items during surprise visits to the medical, pediatric, surgical, and critical care units, and the kitchens of the audited hospitals. Where satisfaction of an item was not possible by observation, a response obtained by staff questioning was accepted. The audit members comprised six infectious diseases consultants divided into three teams. Each team was assigned to review two different hospitals every year for four consecutive years.

Eleven areas of infection control service were identified for the audit, namely: hand washing, environmental cleaning, waste disposal, handling of clean linen, handling of soiled linen, standard and transmission-based precautions, single use policy, urinary catheter care, sterile wound dressing, food hygiene, and pests and animal control in clinical areas. The details of the items audited under each of these eleven areas are shown in an additional file [See Additional File 1]. The hospitals were expected to follow the guideline for isolation precautions in hospitals recommended by the Centers for Disease Control and Prevention (CDC) in 1996 [4]. Any negative or unsatisfactory finding was given a score of zero; any positive or satisfactory finding was given a score of one; 
any partially met finding was given half a mark. When an item was not applicable to the hospital, it was marked as "non-applicable" (NA). Non-applicable items were not included in the final numeric score. If an item audited in different units in the same hospital received different scores, the lowest score was taken as the final score of that item. The total maximum score for handwashing was 21 marks, for environmental cleaning and sanitation, 19 marks, for waste disposal, 20 marks, for handling and storage of clean linen, 5 marks, for handling and storage of soiled linen, 10 marks, for standard and transmissionbased precautions (contact, droplet, and airborne precautions), 32 marks, for single use policy, 3 marks, for urinary catheter drainage, 5 marks, for sterile wound dressing, 11 marks, for food hygiene, 13 marks, and for vector control in clinical areas, 6 marks. The percentage score of any area was calculated as the total marks obtained for the different items audited in the area (the numerator), divided by the total marks of the audited items (the denominator), and multiplied by a hundred.

In addition to the aforementioned areas, the audit included collecting information about the presence of an infection control committee in the hospital, whether the committee met regularly, whether the meetings were appropriately minuted, the number of infection control team staff, the presence of educational activities on infection control directed to health care workers, and the presence of surveillance data.

\section{Feedback to the audited hospitals}

The result of the audit for each hospital was confidentially sent to it within four weeks after the end of Hajj. Hospitals were expected to utilize the results of these audits to improve their infection control services.

\section{Results}

On average, 12-16 hours were required by any of the three teams to complete the audit of each hospital. Tables $1,2,3,4,5,6$ summarize the results of the audits for the six hospitals for four consecutive years. Figure 1 depicts the trends in the annual total percent scores on the eleven audited infection control items for the six hospitals. HGH had the highest score in the four audits with further improvement observed every year. The infection control unit in HGH was chaired by an active and well qualified microbiologist who was able to utilize and take advantage of the results of the audits to further improve the infection control service. Further, the hospital administration was extremely supportive to the infection control unit and the

Table I: Results of the infection control audits for Ajiad Hospital for four consecutive years

\begin{tabular}{|c|c|c|c|c|}
\hline Year & 2003 & 2004 & 2005 & 2006 \\
\hline Total number of beds & 140 & 140 & 140 & 140 \\
\hline Number of critical care beds & 18 & 18 & 18 & 18 \\
\hline Infection control committee in place & No & No & Yes & Yes \\
\hline Infection control committee constituted of representative members & NA & NA & Yes & Yes \\
\hline Regular infection control committee meetings & NA & NA & Yes & Yes \\
\hline Adequate infection control committee minutes & NA & NA & Yes & Yes \\
\hline Infection control unit & Yes & Yes & Yes & Yes \\
\hline Number of infection control team staff & 2 & 4 & 5 & 5 \\
\hline Nurses & I & 2 & 2 & 2 \\
\hline Environmental inspectors & I & I & I & 1 \\
\hline Doctors & 0 & I & I & 1 \\
\hline Microbiologists & 0 & 0 & 1 & 1 \\
\hline Educational activities & No & No & Yes & Yes \\
\hline Surveillance system & No & No & Yes & Yes \\
\hline Area audited & \multicolumn{4}{|c|}{ Percent scores } \\
\hline Handwashing & 16 & 61 & 59 & 77 \\
\hline Environmental cleaning & 50 & 56 & 62 & 58 \\
\hline Waste disposal & 0 & 50 & 82 & 82 \\
\hline Handling of clean linen & 0 & 60 & 60 & 70 \\
\hline Handling of soiled linen & 0 & 50 & 70 & 60 \\
\hline Standard and transmission based precautions & 29 & 36 & 50 & 56 \\
\hline Single use policy & 33 & 33 & 67 & 50 \\
\hline Urinary catheter care & 40 & 40 & 60 & 80 \\
\hline Sterile wound dressing & 64 & 64 & 73 & 69 \\
\hline Food hygiene & 54 & 69 & 69 & 83 \\
\hline Pests and animal control in clinical areas & 67 & 67 & 67 & 67 \\
\hline Average total percent score & 32 & 53 & 65 & 68 \\
\hline
\end{tabular}

NA: not applicable. 
Table 2: Results of the infection control audits for Alnoor Specialist Hospital for four consecutive years

\begin{tabular}{|c|c|c|c|c|}
\hline Year & 2003 & 2004 & 2005 & 2006 \\
\hline Total number of beds & 650 & 557 & 557 & 557 \\
\hline Number of critical care beds & 43 & 43 & 43 & 43 \\
\hline Infection control committee in place & Yes & Yes & Yes & Yes \\
\hline Infection control committee constituted of representative members & Yes & Yes & Yes & Yes \\
\hline Regular infection control committee meetings & Yes & Yes & Yes & Yes \\
\hline Adequate infection control committee minutes & Yes & Yes & Yes & Yes \\
\hline Infection control unit & Yes & Yes & Yes & Yes \\
\hline Number of infection control team staff & 4 & 4 & 7 & 7 \\
\hline Nurses & 3 & 3 & 2 & 2 \\
\hline Environmental inspectors & 0 & 0 & 3 & 3 \\
\hline Doctors & 0 & 0 & I & $\mathrm{I}$ \\
\hline Microbiologists & 1 & 1 & 1 & 1 \\
\hline Educational activities & No & No & Yes & Yes \\
\hline Surveillance system & No & No & Yes & Yes \\
\hline Area audited & \multicolumn{4}{|c|}{ Percent scores } \\
\hline Handwashing & 61 & 61 & 79 & 91 \\
\hline Environmental cleaning & 78 & 78 & 78 & 90 \\
\hline Waste disposal & 62 & 73 & 86 & 95 \\
\hline Handling of clean linen & 60 & 60 & 60 & 90 \\
\hline Handling of soiled linen & 50 & 50 & 60 & 78 \\
\hline Standard and transmission based precautions & 45 & 48 & 77 & 83 \\
\hline Single use policy & 33 & 33 & 100 & 83 \\
\hline Urinary catheter care & 80 & 80 & 80 & 80 \\
\hline Sterile wound dressing & 64 & 73 & 82 & 92 \\
\hline Food hygiene & 67 & 67 & 75 & 73 \\
\hline Pests and animal control in clinical areas & 100 & 100 & 83 & 92 \\
\hline Average total percent score & 64 & 66 & 78 & 86 \\
\hline
\end{tabular}

infection control committee. Any recommendations to improve the infection control practice were given the highest priority by the hospital administration. KFH also had remarkable improvement of its audit score with approximately $20 \%$ increment in the total average score every year in the first three years. The main reason for the improvement observed in KFH was also the remarkable administrative commitment and dedication to resolve the deficiencies reported in the audits and to follow the audit's recommendations. The other four hospitals also showed steady, albeit less remarkable, improvements in all aspects of the audit.

Handwashing scored low in all hospitals in the first audit but it markedly improved in the subsequent audits mainly due to the use of waterless alcohol handrub as an alternative to handwashing with water and soap. Another important infection control deficiency observed in most of the hospitals was the limited understanding and implementation of standard and transmission-based precautions. All hospitals were following old isolation guidelines when the first audit was conducted in year 2003. The new isolation guidelines recommended by the CDC were implemented in the subsequent years but the improvement was somewhat slow as the process of educating and training HCWs on these new concepts of isolation was rather long.
The rate of improvement of the audit score in the first three years was somewhat faster than that for the fourth year (Figure 1). The initial fast improvement was mainly attributed to resolving infection control deficiencies that required no extra-resources. The slower improvement noticed subsequently was attributable to infetion control items that required extra-resources to be resolved or improved as it took hospitals one to three years to get such extra-resources secured.

\section{Discussion}

Clinical audit is a quality improvement process that seeks to improve patient care and outcomes through systematic review of care against explicit criteria and the implementation of change [5]. The so called, audit cycle, comprises five basic stages: choosing a topic, specifying appropriate practice standards, testing actual practice against these standards (data collection), correcting practice where it falls short, and finally, re-auditing to confirm that standards are met [6,7]. Attainment of standards may only be achieved after several rounds of the audit cycle [7].

Hospital infection control is a good subject for audit as it affects patient care, quality of life and clinical outcomes [7]. Additionally, evidence-based standards of practice have been developed [6-10]. It is now accepted that audit 
Table 3: Results of the infection control audits for King Abdulaziz Hospital for four consecutive years

\begin{tabular}{|c|c|c|c|c|}
\hline Year & 2003 & 2004 & 2005 & 2006 \\
\hline Total number of beds & 272 & 272 & 272 & 272 \\
\hline Number of critical care beds & 30 & 30 & 30 & 30 \\
\hline Infection control committee in place & No & No & No & Yes \\
\hline Infection control committee constituted of representative members & NA & NA & NA & Yes \\
\hline Regular infection control committee meetings & NA & NA & NA & Yes \\
\hline Adequate infection control committee minutes & NA & NA & NA & Yes \\
\hline Infection control unit & No & No & Yes & Yes \\
\hline Number of infection control team staff & 1 & I & 4 & 6 \\
\hline Nurses & I & I & 2 & 2 \\
\hline Environmental inspectors & 0 & 0 & 1 & 2 \\
\hline Doctors & 0 & 0 & I & 2 \\
\hline Microbiologists & 0 & 0 & 0 & 0 \\
\hline Educational activities & No & No & Yes & Yes \\
\hline Surveillance system & No & No & Yes & Yes \\
\hline Area audited & \multicolumn{4}{|c|}{ Percent scores } \\
\hline Handwashing & 10 & 32 & 57 & 57 \\
\hline Environmental cleaning & 16 & 22 & 54 & 58 \\
\hline Waste disposal & 5 & 18 & 50 & 50 \\
\hline Handling of clean linen & 0 & 0 & 40 & 40 \\
\hline Handling of soiled linen & 0 & 40 & 50 & 44 \\
\hline Standard and transmission based precautions & 29 & 29 & 59 & 72 \\
\hline Single use policy & 33 & 33 & 67 & 67 \\
\hline Urinary catheter care & 60 & 80 & 60 & 67 \\
\hline Sterile wound dressing & 0 & 45 & 80 & 70 \\
\hline Food hygiene & 54 & 69 & 69 & 62 \\
\hline Pests and animal control in clinical areas & 17 & 17 & 33 & 83 \\
\hline Average total percent score & 20 & 35 & 56 & 61 \\
\hline
\end{tabular}

NA: not applicable.

is a key function for infection control teams $[7,11,12]$. Audit programs should include audits of infection control policies in wards and departments, microbiological safety and cleanliness audits of the hospital environment, and audits of standard healthcare equipment [7].

The most effective strategies to prevent health care associated infections include audit of the incidence of infection, feedback of these infection rates to clinical staff, continuous infection control education programs, one infection control nurse for every 250 beds, and infection control audit for evaluating clinical practice [13]. The results of the current study confirmed the enormous positive impact of audits on infection control service and practice. All six hospitals had tangible improvements of all aspects of infection control. The improvement was most pronounced in hospitals that obtained the lowest scores in the first audit. Early feedback of the results of the audits to the concerned hospitals was essential for the hospitals to resolve the weaknesses and maintain the strengths. The availability of qualified and well trained personnel and support of the infection control services and committees by the hospital administration were the main driving forces for proper utilization of the audits' results that lead to noticeable improvement in infection control services.

Many deficiencies observed in the first audit were subsequently resolved. AGH and KAH had no infection control committees and $\mathrm{KAH}$ and $\mathrm{MCH}$ had no infection control units in the first year of the audit. Subsequently, appropriate infection control committees and units were established in these hospitals. Notably, all hospitals except HGH had no infection control educational activities when audited first. Subsequently, such activities were initiated. At the outset, all hospitals had no proper surveillance system for health care associated infections. This defect was also resolved in the subsequent years. HGH had four infection control staff (one staff per 65 beds) throughout the study period. The other five hospitals that had shortage of infection control staff (nurses, environmental inspectors, doctors, and/or microbiologists) managed to recruit more staff over the study period. AGH increased the number of infection control staff from two to five staff (one staff per 28 beds), NSH, from four to seven staff (one staff per 80 beds), KAH, from none to six staff (one staff per 45 beds), KFH, from two to three staff (one staff per 
Table 4: Results of the infection control audits for King Faisal Hospital for four consecutive years

\begin{tabular}{|c|c|c|c|c|}
\hline Year & 2003 & 2004 & 2005 & 2006 \\
\hline Total number of beds & 207 & 207 & 207 & 207 \\
\hline Number of critical care beds & 22 & 22 & 22 & 22 \\
\hline Infection control committee in place & Yes & Yes & Yes & Yes \\
\hline Infection control committee constituted of representative members & Yes & Yes & Yes & Yes \\
\hline Regular infection control committee meetings & Yes & Yes & Yes & Yes \\
\hline Adequate infection control committee minutes & Yes & Yes & Yes & Yes \\
\hline Infection control unit & Yes & Yes & Yes & Yes \\
\hline Number of infection control team staff & 2 & 2 & 3 & 3 \\
\hline Nurses & 2 & 2 & 2 & 2 \\
\hline Environmental inspectors & 0 & 0 & 0 & 0 \\
\hline Doctors & 0 & 0 & I & $\mathrm{I}$ \\
\hline Microbiologists & 0 & 0 & 0 & 0 \\
\hline Educational activities & No & No & Yes & Yes \\
\hline Surveillance system & No & Yes & Yes & Yes \\
\hline Area audited & \multicolumn{4}{|c|}{ Percent scores } \\
\hline Handwashing & 30 & 57 & 76 & 95 \\
\hline Environmental cleaning & 69 & 77 & 82 & 93 \\
\hline Waste disposal & 36 & 50 & 91 & 96 \\
\hline Handling of clean linen & 40 & 60 & 80 & 100 \\
\hline Handling of soiled linen & 30 & 60 & 70 & 89 \\
\hline Standard and transmission based precautions & 29 & 57 & 88 & 78 \\
\hline Single use policy & 33 & 33 & 67 & 83 \\
\hline Urinary catheter care & 80 & 80 & 80 & 100 \\
\hline Sterile wound dressing & 44 & 67 & 78 & 100 \\
\hline Food hygiene & 8 & 62 & 85 & 100 \\
\hline Pests and animal control in clinical areas & 67 & 83 & 100 & 67 \\
\hline Average total percent score & 42 & 62 & 82 & 91 \\
\hline
\end{tabular}

69 beds), and the $\mathrm{MCH}$, from two to four staff (one staff per 65 beds). The number of infection control nurses per beds was $1 / 70$ for AGH, 1/186 for NSH, 1/136 for KAH, $1 / 103$ for $\mathrm{KFH}$, and $1 / 130$ each for $\mathrm{MCH}$ and $\mathrm{HGH}$. These ratios were better than the recommended ratios for effective infection control programs [14-16].

Handwashing scored low in all hospitals in the first audit but it markedly improved in the subsequent audits mainly due to the use of waterless alcohol handrub as an alternative to handwashing with water and soap. Other observational studies indicate that, eventhough handwashing is known to be the single most important means of preventing the spread of micro-organisms in the healthcare setting, adherence of health care workers to handwashing practice is low with mean baseline rates of $5 \%-81 \%$, and an overall average of $40 \%$ [17]. A recent study from Saudi Arabia showed that the overall frequency of handwashing after patient contact among health care workers in medical and surgical wards in a tertiary care center in Riyadh was only $23.7 \%$ [18]. Reported risk factors for poor adherence to recommended hand hygiene practices include handwashing agents causing irritation and dryness, sinks that are inadequate in number or inconveniently located, and lack of soap and paper towels $[17,19]$. Easy access to hand hygiene supplies, whether sink, soap, medicated detergent, or alcohol-based hand-rub solution, is essential for optimal adherence to hand hygiene recommendations. In this study, improvement of hand hygiene score in the audited hospitals was mainly due to the use of alcohol handrub as an alternative to hand washing with water and soap. Providing easy access to hand hygiene materials is achievable in the majority of health-care facilities [19]. In contrast to sinks used for handwashing or antiseptic handwash, dispensers for alcohol-based hand rubs do not require plumbing and can be made available adjacent to each patient's bed and at many other locations in patient care areas. Further, using alcohol-based hand rubs may be a better option than conventional handwashing with plain or antiseptic soap and water as they require less time, act faster, and irritate hands less often [20-24]. Additionally, their use was shown to lead to a sustained improvement in adherence to hand hygiene and decreased infection rates and to be cost effective [25]. The deficiencies observed in the other items of infection control (environmental cleaning, waste disposal, handling of clean linen, handling of soiled linen, standard and transmission based precautions, single use policy, urinary catheter care, sterile wound dressing, food hygiene, and pests and animal control in clinical areas) were likewise resolved or improved over the study period in the audited hospitals. 
Table 5: Results of the infection control audits for the Maternity and Children Hospital for four consecutive years

\begin{tabular}{|c|c|c|c|c|}
\hline Year & 2003 & 2004 & 2005 & 2006 \\
\hline Total number of beds & 250 & 250 & 250 & 250 \\
\hline Number of critical care beds & 24 & 24 & 24 & 24 \\
\hline Infection control committee in place & Yes & Yes & Yes & Yes \\
\hline Infection control committee constituted of representative members & Yes & Yes & Yes & Yes \\
\hline Regular infection control committee meetings & No & No & Yes & Yes \\
\hline Adequate infection control committee minutes & No & No & Yes & Yes \\
\hline Infection control unit & No & No & Yes & Yes \\
\hline Number of infection control team staff & 2 & 2 & 4 & 4 \\
\hline Nurses & 2 & 2 & 2 & 2 \\
\hline Environmental inspectors & 0 & 0 & 0 & 0 \\
\hline Doctors & 0 & 0 & 2 & 2 \\
\hline Microbiologists & 0 & 0 & 0 & 0 \\
\hline Educational activities & No & No & Yes & Yes \\
\hline Surveillance system & No & No & Yes & Yes \\
\hline Area audited & \multicolumn{4}{|c|}{ Percent scores } \\
\hline Handwashing & 48 & 65 & 78 & 68 \\
\hline Environmental cleaning & 33 & 33 & 62 & 58 \\
\hline Waste disposal & 27 & 41 & 59 & 61 \\
\hline Handling of clean linen & 20 & 20 & 40 & 60 \\
\hline Handling of soiled linen & 0 & 10 & 33 & 57 \\
\hline Standard and transmission based precautions & 29 & 32 & 76 & 89 \\
\hline Single use policy & 33 & 33 & 67 & 75 \\
\hline Urinary catheter care & 60 & 80 & 100 & 60 \\
\hline Sterile wound dressing & 55 & 55 & 91 & 64 \\
\hline Food hygiene & 46 & 62 & 69 & 75 \\
\hline Pests and animal control in clinical areas & 33 & 33 & 33 & 83 \\
\hline Average total percent score & 35 & 42 & 64 & 68 \\
\hline
\end{tabular}

Table 6: Results of the infection control audits for Heraa General Hospital for four consecutive years

\begin{tabular}{|c|c|c|c|c|}
\hline Year & 2003 & 2004 & 2005 & 2006 \\
\hline Total number of beds & 261 & 261 & 261 & 261 \\
\hline Number of critical care beds & 21 & 21 & 21 & 21 \\
\hline Infection control committee in place & Yes & Yes & Yes & Yes \\
\hline Infection control committee constituted of representative members & Yes & Yes & Yes & Yes \\
\hline Regular infection control committee meetings & Yes & Yes & Yes & Yes \\
\hline Adequate infection control committee minutes & Yes & Yes & Yes & Yes \\
\hline Infection control unit & Yes & Yes & Yes & Yes \\
\hline Number of infection control team staff & 4 & 4 & 4 & 4 \\
\hline Nurses & 2 & 2 & 2 & 2 \\
\hline Environmental inspectors & I & I & I & I \\
\hline Doctors & 0 & 0 & 0 & 0 \\
\hline Microbiologists & 1 & I & I & I \\
\hline Educational activities & Yes & Yes & Yes & Yes \\
\hline Surveillance system & No & Yes & Yes & Yes \\
\hline Area audited & \multicolumn{4}{|c|}{ Percent scores } \\
\hline Handwashing & 52 & 83 & 83 & 93 \\
\hline Environmental cleaning & 94 & 94 & 83 & 84 \\
\hline Waste disposal & 60 & 91 & 96 & 98 \\
\hline Handling of clean linen & 75 & 75 & 100 & 100 \\
\hline Handling of soiled linen & 90 & 90 & 90 & 90 \\
\hline Standard and transmission based precautions & 42 & 86 & 91 & 89 \\
\hline Single use policy & 33 & 67 & 100 & 100 \\
\hline Urinary catheter care & 80 & 100 & 100 & 100 \\
\hline Sterile wound dressing & 82 & 91 & 100 & 100 \\
\hline Food hygiene & 50 & 83 & 92 & 96 \\
\hline Pests and animal control in clinical areas & 83 & 100 & 67 & 75 \\
\hline Average total percent score & 67 & 87 & 91 & 93 \\
\hline
\end{tabular}




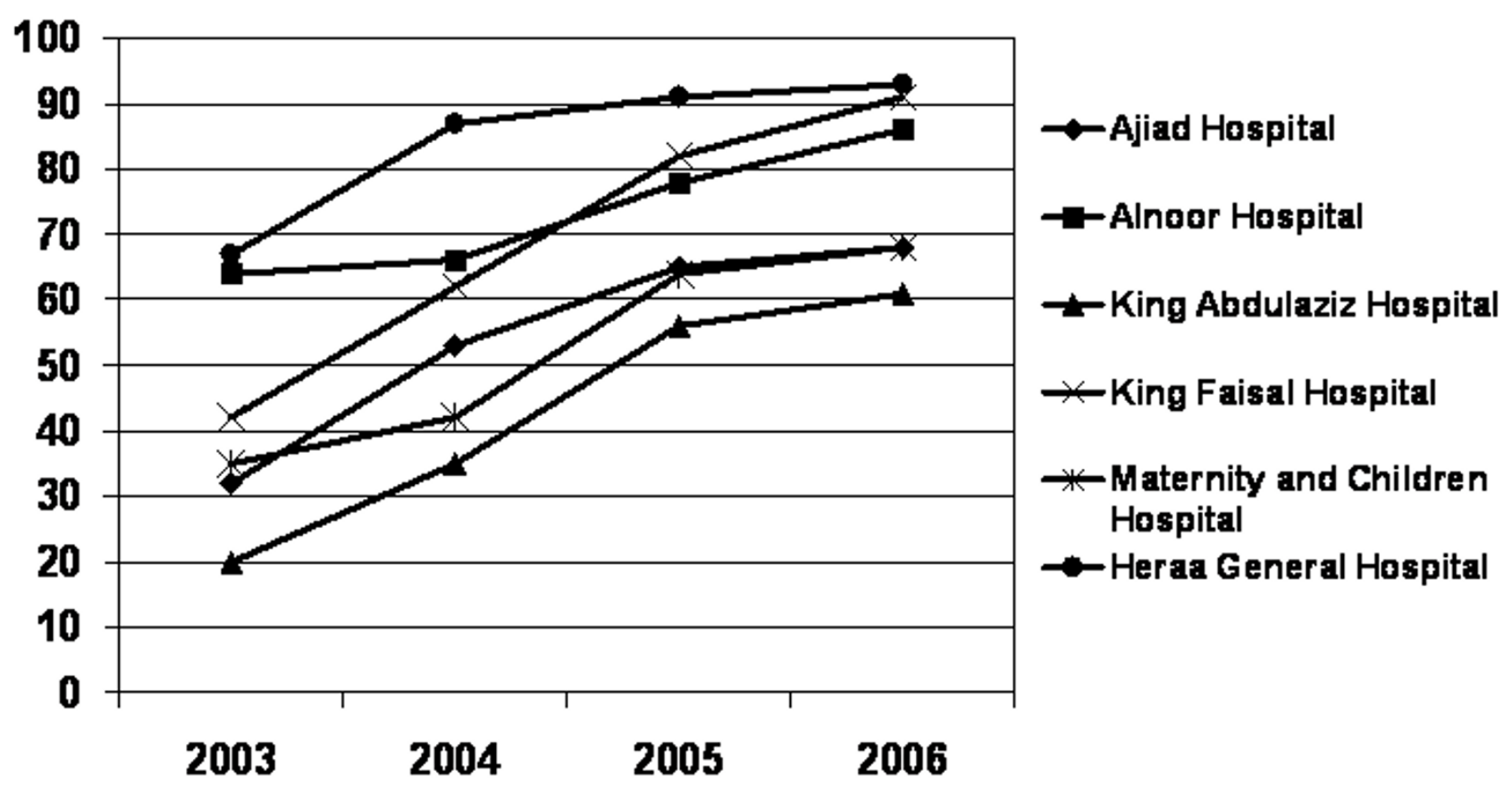

Figure I

Trends of the annual total percent scores on eleven audited infection control areas in six community hospitals in Makkah, Saudi Arabia for four consecutive years (2003-2006).

Previous studies evaluating the effects of audit and feedback on professional practice and health care outcomes showed variable results (25-26). Cochrane reviews of these studies conclude that audit and feedback yield a small to modest improvement in the practice of health care professionals, regardless of whether they are used alone or in concert with other forms of intervention (2526). The relative effectiveness of audit and feedback is likely to be greater when baseline adherence to recommended practice is low and when feedback is delivered more intensively (25). These reviews were hampered by the fact that many published studies are too small, not rigorously designed and lack detailed descriptions of interventions (6). Our study demonstrated a substantial positive impact of audit and feedback on infection control practice. There were, however, some limitations of this study. The eleven areas audited in this study were not all- inclusive. Several other areas were not included in the audits such as infection control in the hemodialysis units, central sterile supply departments, operating, delivery, and emergency rooms, laboratories, pharmacies, and outpatient departments. Further, the impact of the improvement of infection control practice on the rate of healthcare associated infections in the audited hospitals was not assessed in this study. It is conceivable, however, that such improvement in infection control practice would have had a significant positive impact on the rate of health-care associated infections as the audits included items that are considered to be evidence-based standards of practice in infection control to prevent health-care associated infections [6-10].

In conclusion, regular hospital infection control audits lead to significant improvement of infection control prac- 
tice and hence improvement of patient safety. Infection control should be a top priority in hospitals. There is a need to build a rigorous infection control audit into hospitals' ongoing monitoring and reporting to the $\mathrm{MOH}$ and to provide these hospitals with feed back on such audits to continuously strengthen the safety standards for patients, visitors, and employees.

\section{Competing interests}

The author(s) declare that they have no competing interests.

\section{Authors' contributions}

TAM designed the study and the audit tool, participated in auditing the hospitals, analyzed the data, and wrote the manuscript. AMB, MAH, TAA, AOT, and AHI participated in designing the audit tool and auditing the hospitals. All authors read and approved the final manuscript.

\section{Additional material}

\section{Additional File 1}

Infection control items audited. The table shows the details of the infection control items audited

Click here for file

[http://www.biomedcentral.com/content/supplementary/14712334-6-135-S1.doc]

\section{References}

I. Madani TA, Al-Mazrou YY, Al-Jeffri MH, Mishkhas AA, Al-Rabeah AM, Turkistani AM, Al-Sayed MO, Abodahish AA, Khan AS, Ksiazek TG, Shobokshi O: Rift Valley Fever Epidemic in Saudi Arabia; Epidemiological, Clinical, and Laboratory Characteristics. Clin Infect Dis 2003, 37(8): 1084-1092.

2. Madani TA: Alkhumra Virus Infection, a New Viral Hemorrhagic Fever in Saudi Arabia. J Infect 2005, 5 I (2):9|-97.

3. Website title [http://www.health.vic.gov.au/infcon/gramp/
(n) ic check.pdf.]

4. Guideline for isolation precautions in hospitals. Part II. Recommendations for isolation precautions in hospitals. Hospi tal Infection Control Practices Advisory Committee. Am J Infect Control 1996, 24(I):32-52.

5. National Institute for Clinical Excellence: Principles for best practice in clinical audit Oxford: Radcliffe Medical Press; 2002.

6. French GL: Closing the loop: audit in infection control. J Hosp Infect 1993, 24:301-308.

7. Hay A: Audit in infection control. J Hosp Infect 2006, 62:270-277.

8. Pratt RJ, Pellowe C, Loveday HP, Robinson N, Smith GW, Barrett S, Davey P, Harper P, Loveday C, McDougall C, Mulhall A, Privett S, Smales C, Taylor L, Weller B, Wilcox M, Department of Health (England): The epic project: developing national evidence-based guidelines for preventing healthcare associated infections. Hosp Infect 200I, 47(Suppl):S3-S82.

9. Pellowe CM, Pratt RJ, Harper P, Loveday HP, Robinson N, Jones SR, MacRae D, Mulhall A, Smith GW, Bray J, Carroll A, Chieveley Williams S, Colpman D, Cooper L, Mclnnes E, McQuarrie I, Newey JA Peters J, Pratelli N, Richardson G, Shah PJ, Silk D, Wheatley C, Guideline Development Group: Prevention of healthcare-associated infections in primary and community care. J Hosp Infect 2003, 55(Suppl 2):S5-SI27.

10. Combined Working Party of the British Society for Antimicrobial Chemotherapy the Hospital Infection Society and the Infection Control Nurses Association: Revised guidelines for the control of methicillin-resistant Staphylococcus aureus infection in hospitals. J Hosp Infect 1998, 39:253-290.

II. Hospital Infection Working Group of the Department of Health and Public Health Laboratory Service: Hosp Infect Control UK: Department of Health; 1995

12. The Scottish Office Department of Health Advisory Group on Infection: . In Scottish infection manual Edinburgh: The Scottish Office Department of Health; 1998.

13. Horton R: Introducing high quality infection control in a hospital setting. BrJ Nurs 1993, 2(15):746-750.

14. Haley RW, Culver DH, White JW, Morgan WM, Emori TG, Munn VP, Hooton TM: The efficacy of infection surveillance and control programs in preventing nosocomial infections in US hospitals. Am J Epidemiol 1985, I 2 I: 182-205.

15. Scheckler WE, Brimhall D, Buck AS, Farr BM, Friedman C, Garibaldi RA, Gross PA, Harris JA, Hierholzer WJ Jr, Martone WJ, McDonald LL, Solomon SL: Requirements for infrastructure and essential activities of infection control and epidemiology in hospitals: a consensus panel report. Society for Healthcare Epidemiology of America. Am J Infect Control 1998, 26:47-60.

16. Health Canada, Division of Occupational and Nosocomial Infections : Development of a resource model for infection prevention and control programs in acute, long term, and home care settings: conference proceedings of the Infection Prevention and Control Alliance. Can J Infect Control 200I:35-39.

17. Boyce JM, Pittet D, Healthcare Infection Control Practices Advisory Committee; HICPAC/SHEA/APIC/IDSA Hand Hygiene Task Force: Guideline for Hand Hygiene in Health-Care Settings. Recommendations of the Healthcare Infection Control Practices Advisory Committee and the HICPAC/SHEA/APIC/ IDSA Hand Hygiene Task Force. Society for Healthcare Epidemiology of America/Association for Professionals in Infection Control/Infectious Diseases Society of America. MMWR Recomm Rep 2002, 5 I (RR- I 6): I -45.

18. Basurrah MMA, Madani TA: Handwashing and gloving practice among health care workers in medical and surgical wards in a tertiary care center in Riyadh, Saudi Arabia. Scand J Infect Dis 2006, 38:620-624.

19. Pittet D: Improving compliance with hand hygiene in hospitals. Infect Control Hosp Epidemiol 2000, 2 1:38I-386.

20. Voss A, Widmer AF: No time for handwashing! Handwashing versus alcoholic rub: can we afford $100 \%$ compliance? Infect Control Hosp Epidemiol 1997, 18:205-208.

21. Larson E: Skin hygiene and infection prevention: more of the same or different approaches? Clin Infect Dis 1999 , 29:1287-I294.

22. Boyce JM, Kelliher S, Vallande N: Skin irritation and dryness associated with two hand-hygiene regimens: soap-and-water handwashing versus hand antisepsis with an alcoholic hand gel. Infect Control Hosp Epidemiol 2000, 21 :442-448.

23. Winnefeld M, Richard MA, Drancourt M, Grobb J]: Skin tolerance and effectiveness of two hand decontamination procedures in everyday hospital use. $\mathrm{Br} /$ Dermatol 2000, I 43:546-550.

24. Larson EL, Aiello AE, Bastyr J, Lyle C, Stahl J, Cronquist A, Lai L, DellaLatta $P$ : Assessment of two hand hygiene regimens for intensive care unit personnel. Crit Care Med 200I, 29:944-95I.

25. Pittet D, Hugonnet S, Harbarth S, Mourouga P, Sauvan V, Touveneau $\mathrm{S}$ : Effectiveness of a hospital-wide programme to improve compliance with hand hygiene. Lancet 2000, 356:1307-13/2

26. Jamtvedt G, Young JM, Kristoffersen DT, O'Brien MA, Oxman AD: Audit and feedback: effects on professional practice and health care outcomes. Cochrane Database Syst Rev 2006:CD000259.

27. Thomson O'Brien MA, Oxman AD, Davis DA, Haynes RB, Freemantle N, Harvey EL: Audit and feedback versus alternative strategies: effects on professional practice and health care outcomes. Cochrane Database Syst Rev 2000:CD000260.

\section{Pre-publication history}

The pre-publication history for this paper can be accessed here:

http://www.biomedcentral.com/1471-2334/6/135/pre pub 